Revista Brasil. Bot., V.25, n.2, p.177-182, jun. 2002

\title{
Novas espécies de Alstroemeria L. (Alstroemeriaceae) de Minas Gerais, Brasil
}

\begin{abstract}
MARTA C. ASSIS ${ }^{1}$
(recebido: 11 de outubro de 2001; aceito: 21 de fevereiro de 2002)

ABSTRACT - (New species of Alstroemeria L. (Alstroemeriaceae) from Minas Gerais, Brazil). Five new species of Alstroemeria from Minas Gerais, Brazil are described: A. julieae M.C. Assis, A. ochracea M.C. Assis, A. penduliflora M.C. Assis, A. rupestris M.C. Assis and A. variegata M.C. Assis. Descriptions, comments and illustrations are provided.
\end{abstract}

RESUMO - (Novas espécies de Alstroemeria L. (Alstroemeriaceae) de Minas Gerais, Brasil). São descritas cinco novas espécies de Alstroemeria para Minas Gerais, Brasil: A. julieae M.C. Assis, A. ochracea M.C. Assis, A. penduliflora M.C. Assis, A. rupestris M.C. Assis e A. variegata M.C. Assis. São apresentadas descrições, comentários e ilustrações das espécies.

Key words - Alstroemeria, Alstroemeriaceae, Brazil

\section{Introdução}

Alstroemeriaceae é uma família neotropical distribuída desde a região central do México até o Sul da América do Sul com cerca de 180 espécies (Assis 2001). A família é dividida em três gêneros: Alstroemeria L. (incluindo Schickedantzia Pax e Taltalia E. Bayer), Bomarea Mirb. e Leontochir Phil. (Sanso \& Xifreda 2001). No Brasil estão representados os gêneros Alstroemeria L. e Bomarea Mirb.

$\mathrm{O}$ gênero Alstroemeria é caracterizado principalmente por plantas herbáceas, eretas de folhas ressupinadas, inflorescências em cimeira umbeliforme e de flores zigomorfas com padrões de manchas nas tépalas.

No Brasil ocorrem cerca de 39 espécies de distribuição peri-amazônica concentrada basicamente na porção leste do país. Ocorre em quase todos os tipos de hábitats: florestas, cerrados, campos de altitude, brejos, afloramentos rochosos e caatingas, em altitudes que variam de 300 m, na Amazônia, a 2.300 m, na Serra do Itatiaia, sendo que a maioria das espécies tem distribuição relativamente restrita (Assis 2001).

Durante o trabalho de revisão das Alstroemeria do Brasil, várias espécies do gênero foram encontradas nos cerrados, afloramentos rochosos e matas de Minas Gerais e não foram identificadas. A análise acurada evidenciou que se tratavam de novas espécies que são aqui descritas.

Este estudo foi baseado em observações de campo e na análise de materiais botânicos depositados em herbários nacionais e estrangeiros.

1. Centro Nacional de Pesquisa de Monitoramento por Satélite (CNPM/EMBRAPA), Av. Dr. Júlio Soares de Arruda, 803, 13088-300 Campinas, SP, Brasil. marta@cnpm.embrapa.br

\section{Resultados e Discussão}

Alstroemeria julieae M.C. Assis sp. nov.

Herbae foliis chartaceis, glaucis, oblongis vel ellipticis, glabris, in omnibus ramis vegetativis distributis; tepala externa et interna rubro-variegata.

Figuras 1-3.

TIPO: BRASIL: Minas Gerais: São Roque de Minas, Parque Nacional da Serra da Canastra, 21-XI-1998, M.C. Assis et al. 564 (holótipo SPF, isótipo BHCB).

Paratipos: BRASIL: Minas Gerais: São Roque de Minas, Parque Nacional da Serra da Canastra, 20-III-1998, D.V. Arce et al. 3 (SPF); 21-XI-1998, M.C. Assis et al. 564 (SPF); 15-XII-1998, M.A. Farinaccio \& E.M. Campos Filho 245 (SPF); 16-XII-1998, M.A. Farinaccio \& E.M. Campos Filho 262 (SPF); 15-V-1999, M.A. Farinaccio et al. 316 (SPF).

Erva ereta, 0,6-1,2 m alt.; ramos cilíndricos, glabros. Folhas do ramo vegetativo ressupinadas, coriáceas, glaucas, distribuídas por todo o ramo, 2,5-8 $\times 0,9-1,5(-2,2) \mathrm{cm}$, estreito-oblongas ou elípticas, ápice agudo, base cuneada, ambas as faces glabras com nervuras proeminentes. Folhas do ramo reprodutivo ressupinadas, não amplexicaules, coriáceas, glaucas, distribuídas por todo o ramo, 2,5-8 × 0,9-1,5(-2,2) cm, estreito-oblongas ou elípticas, ápice agudo, base cuneada, ambas as faces glabras com nervuras proeminentes. Cimeira umbeliforme simples, raro composta, pedicelo glabro, 3,5-4,5(-10,5) cm compr.; brácteas foliosas, coriáceas, 1,8-5,2(-8) ×0,3-0,7 cm; bractéolas cartáceas, $0,6-4 \times 0,2-0,8 \mathrm{~cm}$. Flores patentes, sem odor, campanuladas, 3,5-4,5 cm compr.; tépalas externas rosadas ou avermelhadas, rubro-variegadas, 
semelhantes entre si, espatuladas, ápice apiculado, base atenuada, a superior $4 \times 0,9 \mathrm{~cm}$, as inferiores $3,1 \times$ $0,9 \mathrm{~cm}$; tépalas internas rosadas ou avermelhadas, rubro-maculadas e variegadas, semelhantes entre si, espatuladas, ápice cuspidado, base atenuada, margem distal inteira ou ligeiramente crenulada, as superiores $3,9 \times 0,9 \mathrm{~cm}$, a inferior $3,5 \times 0,8 \mathrm{~cm}$; estames inclusos, filetes papilosos no terço proximal, 2-2,4 cm compr.; estigma incluso, estilete glabro, $2,5 \mathrm{~cm}$ compr. Cápsula orbicular ou ovada, $0,9-2 \times 1,2 \mathrm{~cm}$.

Distribuição e fenologia: A. julieae ocorre em cerrados de Minas Gerais, sendo frequiente na Serra da Canastra. Floresce de dezembro a fevereiro e frutifica em março e abril.

Alstroemeria julieae é facilmente reconhecida por apresentar folhas ressupinadas na base e na lâmina, coriáceas, glaucas, oblongas ou elípticas, distribuídas por todo o ramo vegetativo e reprodutivo. Além disso, suas flores possuem as tépalas externas e internas rubro-variegadas. Esta espécie pode ser confundida com A. rupestris M.C. Assis da qual diferencia-se pelo hábito vegetativo e flores. A. rupestris possui folhas ressupinadas só na base, cartáceas, não glaucas, largo-elípticas e as tépalas não são variegadas, as externas não possuem manchas e as internas são rubro-maculadas.

O epíteto específico é uma homenagem à Dra. Julie Dutilh, estudiosa das Liliaceae e Amaryllidaceae, e grande amiga que me apresentou a este grupo fascinante.

\section{Alstroemeria ochracea M.C. Assis sp. nov.}

Herbae foliis membranaceis ad chartacea, supra pappilata; flores flavescentes vel aurantiaci, tepala externa et interna maculata.

Figuras 4-8.

TIPO: BRASIL: Minas Gerais: Aiuruoca, Vale do Matutu, elev. 1.600 m, 24-II-1999, M.C. Assis et al. 599 (holótipo SPF, isótipos BHCB, K).

Paratipos: BRASIL: MinAs GeRAIS: Aiuruoca, estrada para o Matutu, 30-I-1996, J.R. Stehmann s.n. (BHCB s.n., UEC79.763).

Ervas eretas, 0,4-1,2 m alt.; ramos cilíndricos, glabros. Folhas do ramo vegetativo ressupinadas, não amplexicaules, membranáceas a cartáceas, distribuídas por todo o ramo ou somente no terço distal, 2,5-9 $\times$ 0,5-2,3 cm, estreitas a largamente elípticas, ápice agudo, base atenuada; face adaxial papilosa com nervuras proeminentes, abaxial glabra. Folhas do ramo reprodutivo ressupinadas, não amplexicaules, membranáceas, distribuídas na metade distal do ramo, 2,5-9 $\times$ 0,5-2,3 cm, estreitas a largamente elípticas, ápice agudo, base atenuada; face adaxial papilosa com nervuras proeminentes e abaxial glabra sem nervuras proeminentes. Cimeira umbeliforme simples, raro composta, pedicelo glabro, $2-8 \mathrm{~cm}$ compr.; brácteas foliosas, membranáceas, 2,5-9 $\times 0,3-2,5 \mathrm{~cm}$; bractéolas membranáceas, $0,8-2 \times 0,1-0,4 \mathrm{~cm}$. Flores patentes, sem odor, campanuladas, 3-4 cm compr.; tépalas externas amarelas ou alaranjadas, rubro-maculadas e pontuadas, semelhantes entre si, estreitamente elípticas, ápice acuminado a cuspidado, base atenuada, a superior ca. $4,3 \times 0,6 \mathrm{~cm}$, as inferiores ca. 3,5 ×0,6 cm; tépalas internas amarelas ou alaranjadas, rubro-listradas e rubro-pontuadas, semelhantes entre si, lineares a lanceoladas, ápice cuspidado, base atenuada, margem distal inteira ou ligeiramente crenulada, as superiores ca. $4 \times 0,3 \mathrm{~cm}$, a inferior ca. $3 \times 0,2 \mathrm{~cm}$; estames inclusos, filetes papilosos no terço proximal, $1,3-3 \mathrm{~cm}$ compr.; estigma incluso, estilete glabro, ca. $3,2 \mathrm{~cm}$ compr. Cápsula elíptica, 1,5-1,7 × 1-1,2 cm.

Distribuição e fenologia: A. ochracea é freqüentemente encontrada no interior ou na borda de matas em Minas Gerais, florescendo de janeiro a abril e frutificando em fevereiro e junho.

Alstroemeria ochracea é de fácil identificação pois possui folhas membranáceas a cartáceas, distribuídas no terço distal ou por todo o ramo vegetativo e as flores são amarelas ou alaranjadas, com tépalas externas rubro-maculadas e pontuadas e as internas rubrolistradas e pontuadas. A. stenopetala Schenk tem flores muito semelhantes às de $A$. ochracea, mas possui folhas coriáceas distribuídas por toda a extensão dos ramos vegetativo e reprodutivo. Além disso, a inflorescência de A. stenopetala é congesta, enquanto em A. ochracea é laxa.

Alstroemeria penduliflora M.C. Assis sp. nov.

Herba foliis chartaceis supra pappilata; flores penduli, rubri apicibus viridibus, bracteis chartaceis perlongis involventes.

Figuras 9-10.

TIPO:BRASIL: MinAS GERAIS: Serra do Cabral, Fazenda Agro-Industrial, $17^{\circ} 42^{\prime}$ S, $44^{\circ} 19^{\prime}$ W, elev. $1.080 \mathrm{~m}$, 11-I-1998, A. Rapini et al. 445 (holótipo SPF, isótipo BHCB).

Paratipos: BRASIL: Minas GeraIs: Joaquim Felício, Serra do Cabral, 7-III-1970, H.S. Irwin et al. 27.092 (SPF); Armazém da Lage, 16-III-1997, G. Hatschbach 


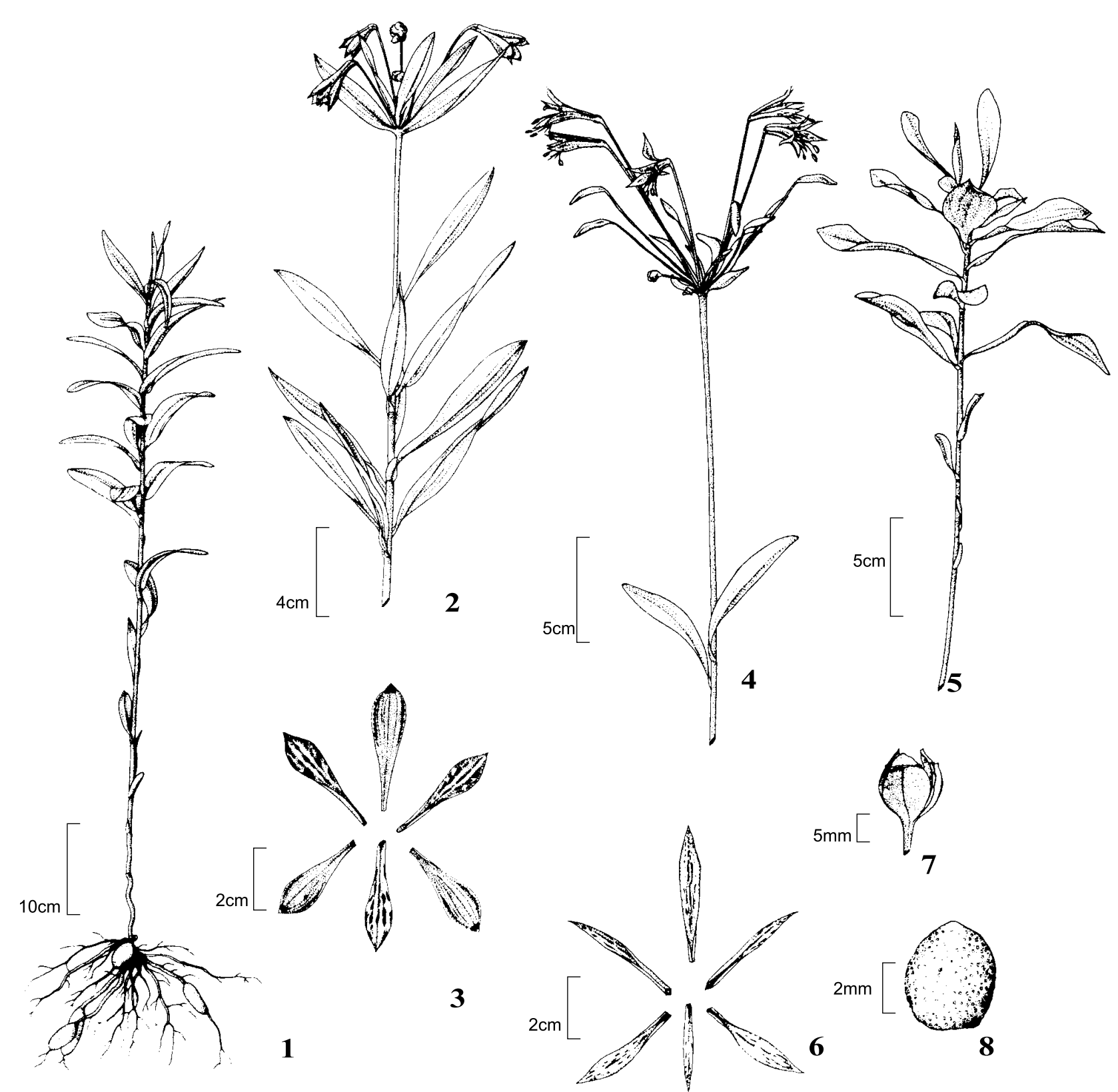

Figuras 1-3. A. julieae. 1. Ramo vegetativo mostrando rizoma e raízes de reserva oblongas. 2. Parte do ramo reprodutivo. 3. Flor mostrando tépalas externas variegadas e internas maculadas. Figuras 4-8. A. ochracea. 4. Ramo reprodutivo. 5. Ramo vegetativo. 6. Flor mostrando tépalas externas pontuadas e maculadas e internas listradas e maculadas. 7 . Fruto maduro e aberto. 8. Semente. (1-3: Assis 564; 4-8: Assis 599).

et al. 66.356 (MBM); Várzea de Palma, Serra do Cabral, 16-I-1996, G. Hatschbach et al. 64.211 (MBM).

Erva 0,7-0,8 m alt.; ramos cilíndricos, glabros. Folhas do ramo vegetativo ressupinadas, não amplexicaules, cartáceas, distribuídas no terço distal do ramo, 2-12 $\times 0,7-3,2 \mathrm{~cm}$, elípticas ou ovadas, face adaxial papilosa com nervuras proeminentes, abaxial glabra. Folhas do ramo reprodutivo ressupinadas, não amplexicaules, cartáceas, distribuídas por todo o ramo,
2-9,5(-12,5) × 0,3-1(-2,3) cm, elípticas ou lanceoladas, ápice acuminado, base atenuada, face adaxial papilosa com nervuras proeminentes, abaxial glabra sem nervuras proeminentes. Cimeira umbeliforme simples, pedicelo glabro, 2-5,5 cm compr.; brácteas envolventes, foliosas, cartáceas, 1,5-8,5 × 0,3-1,5 cm; bractéolas não vistas. Flores pêndulas, sem odor, campanuladas ou ligeiramente tubulosas, 4-4,5 cm compr.; tépalas externas vermelhas, ápice verde, rubro-variegadas, 
semelhantes entre si, espatuladas, ápice acuminado, a superior ca. $3,7 \times 0,6 \mathrm{~cm}$, as inferiores, $3,4 \times 0,8 \mathrm{~cm}$; tépalas internas vermelhas, ápice verde, rubro-maculadas e listradas, semelhantes entre si, linear-espatuladas, ápice cuspidado, base atenuada, margem distal inteira, as superiores ca. $3,8 \times 0,5 \mathrm{~cm}$, a inferior ca. $3,2 \times 0,5 \mathrm{~cm}$; estames inclusos, filetes papilosos no terço proximal, $3,5 \mathrm{~cm}$ compr.; estigma incluso, estilete glabro, $3,5 \mathrm{~cm}$ compr. Cápsula ovóide, $2,2 \times 1,3 \mathrm{~cm}$.

Distribuição e fenologia: A. penduliflora ocorre em afloramentos rochosos e cerrados de altitude na Serra do Cabral, em Minas Gerais. Floresce de janeiro a março e frutifica em janeiro.

Alstroemeria penduliflora é facilmente caracterizada pela inflorescência simples, de flores pêndulas, vermelhas de ápice verde, envoltas por brácteas cartáceas desenvolvidas. As flores são semelhantes às de $A$. isabelleana Herb., no entanto, $A$. isabelleana possui as flores tubulosas e as brácteas são muito reduzidas ou ausentes.

\section{Alstroemeria rupestris M.C. Assis sp. nov.}

Herbae ramis vegetativis foliis chartaceis, glabris, in omnibus ramis distributis; flores rubri, tepala externa sine maculis et interna rubro-maculata.

Figuras 11-13.

TIPO: BRASIL: MinAs GERAIS: Diamantina, Estrada Diamantina - São João da Chapada, afloramento

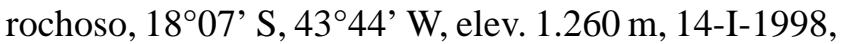
J.R. Pirani et al. 3.989 (holótipo SPF, isótipo BHCB). Paratipos: BRASIL: Minas Gerais: Datas, $18^{\circ} 33^{\prime} \mathrm{S}$, 4338' W, elev. $1.050 \mathrm{~m}, 1-\mathrm{III}-1998$, M.C. Assis et al. 540 (SPF); Diamantina, 7-XII-1997, P.T. Sano et al. 660 (SPF); 10-XII-1997, R.C. Forzza et al. 541 (SPF); 30-I-1998, N.L. Menezes et al. 1.378 (SPF); 11-II-1998, P.T. Sano et al. 824 (SPF); 14-II-1998, P.T. Sano et al. 907 (SPF); 24-II-1999, R.C. Forzza \& S. Buzato 1.087 (SPF).

Erva ereta, 0,8-1,4 $\mathrm{m}$ alt.; ramos cilíndricos, glabros. Folhas do ramo vegetativo ressupinadas, não amplexicaules, cartáceas, distribuídas por todo o ramo, 2,5-12,5 × 2,2-3,5 cm, elípticas, ápice agudo, base atenuada, ambas as faces glabras, nervuras proeminentes na face adaxial. Folhas do ramo reprodutivo ressupinadas, não amplexicaules, cartáceas, distribuídas por todo o ramo, 3-15,5 × 1,6-2,2(-3,3) cm, elípticas, ápice agudo, base atenuada, ambas as faces glabras, nervuras proeminentes na face adaxial. Cimeira umbeliforme simples, pedicelo glabro, 4-5,5 cm compr.; brácteas foliosas, membranáceas, 2-6(-10) $\times$ $0,4-1,2(-1,8) \mathrm{cm}$; bractéolas não vistas. Flores patentes, sem odor, campanuladas, $4,5 \mathrm{~cm}$ compr.; tépalas externas vermelhas, sem manchas, semelhantes entre si, oblanceoladas, ápice apiculado, base atenuada, a superior $3,3 \times 0,8 \mathrm{~cm}$, as inferiores $2,8 \times 0,8 \mathrm{~cm}$; tépalas internas vermelhas, rubro-maculadas, semelhantes entre si, ovado-espatuladas, ápice cuspidado, base atenuada, margem distal inteira ou ligeiramente crenulada, as superiores $4,3 \times 1 \mathrm{~cm}$, a inferior $3,5 \times 0,8 \mathrm{~cm}$; estames inclusos, filetes papilosos no terço proximal, ca. $3 \mathrm{~cm}$ compr.; estigma incluso, estilete glabro, ca. $3,1 \mathrm{~cm}$ compr. Cápsula ovada, $2,2 \times 1,2 \mathrm{~cm}$.

Distribuição e fenologia: A. rupestris é encontrada em afloramentos rochosos no planalto de Diamantina e Itacambira, Minas Gerais, florescendo de dezembro a março e frutificando em março.

Alstroemeria rupestris é uma espécie caracterizada por seu hábito vegetativo com folhas cartáceas distribuídas por todo o ramo. É semelhante a A. julieae e A. monticola Mart. ex Schult. \& Schult. f., mas A. julieae possui folhas coriáceas e todas as tépalas manchadas, enquanto em $A$. rupestris as tépalas extenas não possuem manchas e as internas são maculadas. A. monticola, por sua vez, possui folhas membranáceas, concentradas no terço distal do ramo.

Alstroemeria variegata M.C. Assis sp. nov.

Herba foliis chartaceis congeste distributis in omnibus ramis vegetativis et reproductivis; flores robusti, tepala externa et interna variegata.

Figuras 14-17.

TIPO: BRASIL: Minas GeRAIS: Caldas, Pedra Branca, II-1998, J.H.A. Dutilh 470 (holótipo SPF, isótipo UEC). Paratipos: BRASIL: Minas Gerais: Caldas, Pedra Branca, 6-II-1866, A.F. Regnell III 1.230 (C, P, S); 12-VII-1869, A.F. Regnell III 1.229 (C); 21-XI-1879, A.F. Regnell III 1.796 (C); 21-I-1919, F.C. Hoehne 2.882 (SP); entre rochas, elev. $2.000 \mathrm{~m}, 24-\mathrm{I}-1980$, A. Krapovickas \& C.L. Cristóbal 35.493 (CTES, MBM).

Erva ereta, 0,5-0,8 m alt.; ramos cilíndricos, glabros. Folhas do ramo vegetativo ressupinadas, não amplexicaules, cartáceas, congestamente distribuídas por todo o ramo, 2,3-6,2 ×0,6-1,1 cm, elípticas a oblongas ou espatuladas, ápice agudo, base 
estreitamente atenuada, glabra na face adaxial papilosa, nervuras proeminentes na face adaxial. Folhas do ramo reprodutivo ressupinadas, não amplexicaules, cartáceas, congestamente distribuídas por todo o ramo, 1,2-9 $\times$ 0,5-1,5 cm, elípticas a oblongas ou espatuladas; ápice agudo, base estreitamente atenuada; face adaxial glabra, abaxial papilosa, nervuras proeminentes na face adaxial. Cimeira umbeliforme simples, pedicelo papiloso, 2,5-6 cm compr.; brácteas foliosas, membranáceas $1,5-4,5 \times 0,5-1,3 \mathrm{~cm}$; bractéolas não vistas. Flores patentes, sem odor, campanuladas, robustas, $4,5-5 \mathrm{~cm}$ compr.; tépalas externas vermelhas a amareladas,

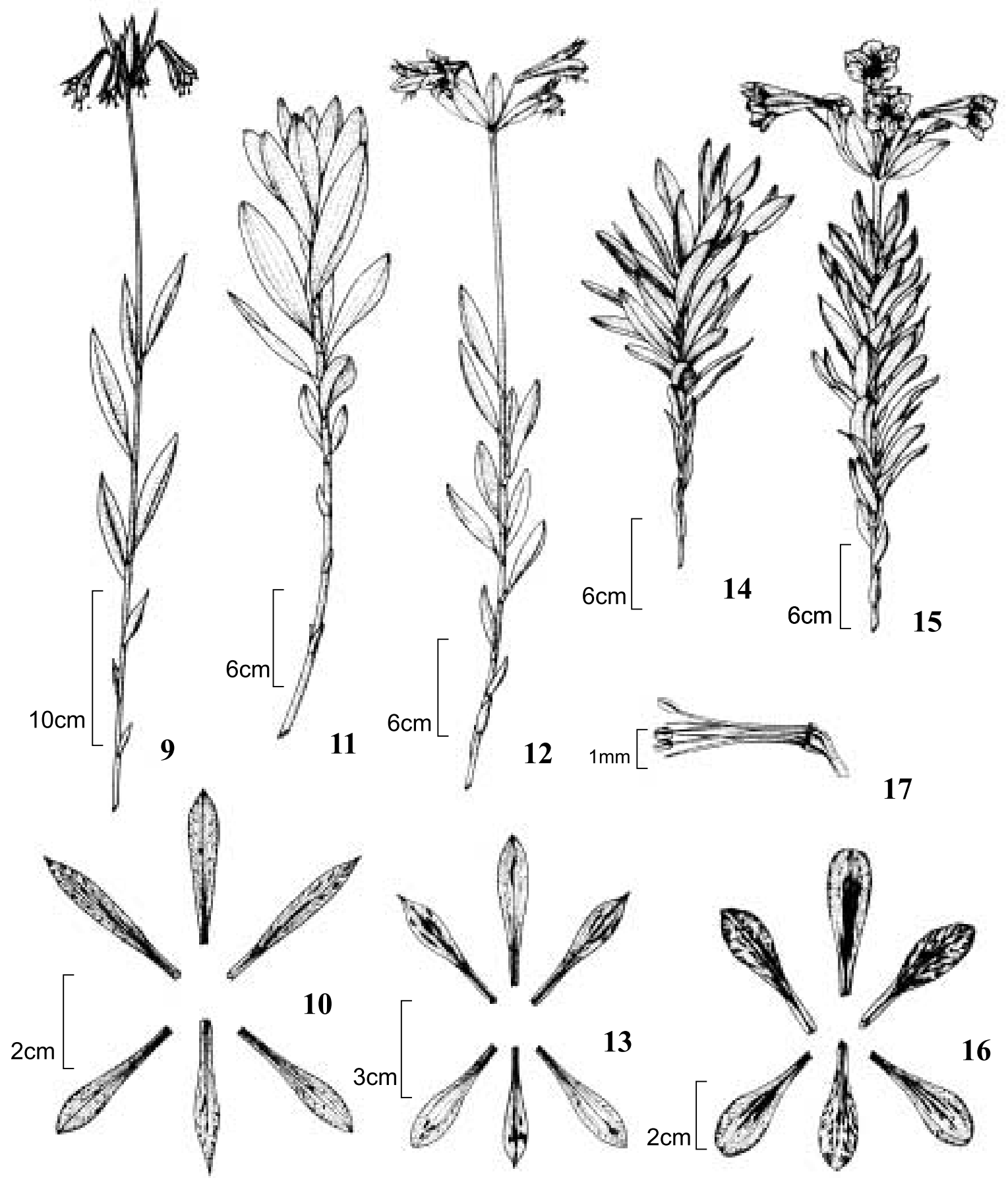

Figuras 9-10. A. penduliflora. 9. Ramo reprodutivo mostrando flores pêndulas. 10. Flor mostrando tépalas internas maculadas e listradas. Figuras 11-13. A. rupestris. 11. Parte do ramo vegetativo. 12. Parte do ramo reprodutivo. 13. Flor mostrando tépalas internas maculadas e listradas. Figuras 14-17. A. variegata. 14. Ramo vegetativo. 15. Ramo reprodutivo. 16. Flor mostrando tépalas externas e internas variegadas, maculadas e listradas. 17. Estames mostrando filetes papilosos no terço proximal. (9-10: Rapini 445; 11-13: Forzza 1.087; 14-17: Dutilh 470). 
rubro-variegadas e maculadas, semelhantes entre si, espatuladas, ápice mucronado, base atenuada, a superior ca. $4,2 \times 1,3 \mathrm{~cm}$, as inferiores $4 \times 1,2 \mathrm{~cm}$; tépalas internas vermelhas a amareladas, rubro-variegadas e maculadas, semelhantes entre si, espatuladas, ápice levemente apiculado, base atenuada, margem distal inteira ou ligeiramente crenulada, as superiores ca. 4,7 $\times 1,4 \mathrm{~cm}$, a inferior ca. $4,1 \times 1,2 \mathrm{~cm}$; estames inclusos, filetes papilosos no terço proximal, ca. $3,2 \mathrm{~cm}$ compr.; estigma incluso, estilete glabro, ca. $3,3 \mathrm{~cm}$ compr. Cápsula imatura turbinada a obcônica, ca. $2 \times 2,2 \mathrm{~cm}$. Distribuição e fenologia: A. variegata é endêmica de Caldas, Minas Gerais, onde é encontrada em altitudes elevadas em afloramentos rochosos. Floresce de novembro a fevereiro e frutifica em janeiro.

Alstroemeria variegata, como o nome indica, caracteriza-se por apresentar as flores com todas as tépalas variegadas. Além disso, as folhas são cartáceas e congestamente distribuídas pelos ramos vegetativo e reprodutivo, o que a torna semelhante a A. foliosa Mart. ex Schult. \& Schult. f. No entanto, as flores de A. foliosa não são variegadas, as tépalas externas não possuem manchas e as internas são rubro-listradas.

Agradecimentos - Agradeço ao Dr. Tarciso de Sousa Filgueiras pelas versões das diagnoses para o latim.

\section{Referências bibliográficas}

ASSIS, M.C. 2001. Alstroemeria L. (Alstroemeriaceae) do Brasil. Tese de doutorado, Universidade de São Paulo, São Paulo.

SANSO, A.M. \& XIFREDA, C.C. 2001. Generic Delimitation between Alstroemeria and Bomarea (Alstroemeriaceae). Annals of Botany 88:1057-1069. 